\title{
The use of capital budgeting techniques in businesses: a perspective from the Western Cape
}

Pradeep Brijlal and Lemay Quesada

\begin{abstract}
Capital budgeting is one of the most important areas of financial management. There are several techniques commonly used to evaluate capital budgeting projects namely the payback period, accounting rate of return, present value and internal rate of return and profitability index. Recent studies highlight that financial managers worldwide favor methods such as the internal rate of return (IRR) or non-discounted payback period (PP) models over the net present value (NPV), which is the model academics consider superior. In particular this research focused on small, medium and large businesses and investigated a number of variables and associations relating to capital budgeting practices in businesses in the Western Cape province of South Africa. The results revealed that payback period, followed by net present value, appears to be the most used method across the different sizes and sectors of business. It was also found that $64 \%$ of businesses surveyed used only one technique, while $32 \%$ of the respondents used between two to three different types of techniques to evaluate capital budgeting decisions. The findings show that the more complicated methods such as IRR and NPV are most favored by the large businesses as compared to the small businesses. The majority of the respondents believed that project definition was the most important stage in the capital budgeting process. Implementation stage appeared to be the most difficult stage for the manufacturing sector whereas Project definition, Analysis and selection and Implementation were generally rated as being the difficult stages by the retail sector. Project definition and Analysis and selection were found to be the most difficult stages by the service sector. Most businesses used the cost of bank loan as a basis in capital budgeting and more than two thirds of respondents used nonquantitative techniques to consider risk when making a decision on investing in fixed assets.
\end{abstract}

\section{INTRODUCTION}

Capital budgeting plays a pivotal role in any organisation's financial management strategy. Gitman (2007) defines it as the "process of evaluating and selecting long term investments that are consistent with the business's goal of maximising owner wealth". Typically every organisation that embarks on 
this process must take all necessary steps to ensure that their decision making criteria supports the business's strategy and enhances its competitive advantage over its rivalries. The realisation that a business leverages its competitive advantage on its resources and on how it undertakes decisions relating to the use of its resources, such as financial resources call for managers to make informed decisions. Managers world over have developed both systematic and non-systematic ways to handling capital budgeting procedures in their organisation. In today's highly competitive environment, managerial decisions are usually but not always based on informed research and information.

Research in the field of capital budgeting has been focussed predominantly in the developed nations. The results may not necessarily be applicable to the developing nations, such as South Africa. Research in this field is rare in developing nations. It will be beneficial to find out the nature of capital budgeting practices in South Africa. Such knowledge will add to theories on modern practice while at the same time will be of great benefit to policy makers and academics in the areas such as financial management, banking, education and training.

This paper reports on the findings of a survey on managers of registered business businesses in the Western Cape Province of South Africa on how they undertook capital budgeting practices. The survey followed similar surveys that were conducted around the globe such as Sandahl \& Sjogren, 2002; Kester \& Chong, 2001; Kester, Chong, Echanis, Haikal, Isa, Skully, Tsui, \& Wang, 1999. The survey is the first one of its kind in South Africa in general and in the Western Cape Province in particular.

\section{LITERATURE REVIEW}

Capital budgeting techniques is defined as the methods and techniques used to evaluate and select an investment project. It helps managers to select projects with the highest profits at an acceptable risk (Verbeeten, 2006). Simple capital budgeting techniques such as payback period and accounting rate of return do not use cash flows and do not consider the time value of money. Sophisticated capital budgeting techniques such as the net present value and the internal rate of return considers risk, cash flows and the time value of money.

Many scholars and researchers agree that capital budgeting decisions are crucial to a business's performance (Arya, Fellingham \& Glover, 1998). Capital budgeting plays a crucial role in a business's competitive model. This explains why Kwak, Shi, Lee \& Lee (1996) state that capital budgeting is not a trivial task. A business whose ability to effectively develop a feasible mechanism for capital budgeting may gain a better competitive advantage to its rivalries in an environment characterised by change and volatility (Lazaridis, 2004).

There are variety of methods and techniques that managers can use to facilitate capital budgeting procedures (Horngren, Foster \& Datar, 1997; Ross, 1995). In practice capital budgeting techniques show divergence from business to business and in some instances from manager to manager. In some instances, theory seems to be ignored by managers in the process of decision-making (McDonald, 1998). 
In the last three decades, empirical research involving both large and small sized businesses has been conducted extensively on the use of capital budgeting techniques. Hermes, Smid \& Yao (2007); Lazaridis (2004); Sandahl \& Sjogren (2002); Kester \& Chong (2001); Kester , Chong, Echanis, Haikal, Isa, Sckully, Tsui \& Wang (1999); Drury \& Tayles (1996) and Jog \& Srivastava (1995) provide details of empirical studies on capital budgeting practices in Asia, Cyprus, Netherlands \& China, Sweden, Canada, Singapore and the UK respectively. These surveys, which have focused on methods of evaluating project profitability and risk, have shown that the sophistication of the analytical techniques used by United States executives has increased over time. Discounted cash flow (DCF) techniques, such as Net Present Value (NPV) and Internal Rate of Retum (IRR), have become the dominant method of evaluating and ranking proposed capital investment (Kester et al (1999).

Hatfield, Horvath, and Webster (1998) as cited by Lazaridus (2004) investigated the importance of payback period (PP), average rate of return (ARR), internal rate of return (IRR) and net present value (NPV) capital budgeting techniques on the performance and value measures of businesses. They found out that businesses analyzing all projects had higher share prices on average as compared to those that did not. Their results thus suggested that businesses should not use single capital budgeting technique but instead should apply as many methods as possible for a project evaluation, in order to maximise the value of a business.

Interestingly Hermes, Smid \& Yao (2007) provide evidence that Dutch managers on average use more sophisticated capital budgeting techniques (IRR and NPV) than Chinese managers tasked with capital decision making. This finding may be attributed, amongst other factors, that the Netherlands is more developed economy compared with China. In comparison South Africa is a developing nation and may show similar results as that of China.

This research presents a description of capital budgeting practices in the Western Cape Province of South Africa. The motivation behind the research centred on the scarcity of empirical research on capital budgeting

practices as compared to other countries such as the United States of America, Britain, China, Netherlands, Canada and Singapore as indicated above. Through this research, additional empirical evidence relating to capital budgeting practices in South Africa was sought. Unlike most studies, which concentrated on large businesses, this research focused on small, medium and large businesses across the different business sectors. A number of variables and associations relating to capital budgeting practices in business businesses in the Western Cape Province of South Africa were investigated. 


\section{METHODOLOGY}

The research sought to gather both quantitative and qualitative data relating to capital budgeting practices in the Western Cape. Data was obtained through a survey of registered businesses ranging from small to large businesses. A convenience sample was used. Managers who were responsible for capital budgeting decisions were targeted. In order to achieve this, a total of 600 managers from the province's different types of businesses ranging from small to medium and large were targeted as potential respondents. These were selected randomly from the directory of businesses in the Western Cape. The directory contains a list of registered businesses in the province, their location and contact details. The respondents were selected randomly from small, medium and large businesses listed on the directory. Due to the nature of capital budgeting practice, the research focused primarily on managers whose mandate included executing capital budgeting decisions in their businesses. In this regard, the survey sought to gather data on the experiences of the decision makers and the day-to-day practice associated with capital budgeting. The population was defined as those businesses that were located in the Western Cape Province, particularly within the Cape Town Metropolitan area. A pilot testing of the original survey interview schedule was first administered to ten managers across the three types of businesses that were studied before being fully utilised with the target respondents. The aim of pilot testing was to clarify and to check the relevance of some questions before interviewing. The informed responses gathered from the pilot survey were incorporated into the final version that was used to conduct the interviews with those managers who agreed to become respondents. A descriptive approach to the research finding was adopted. This was augmented by the chi square test technique that was used to measure association between variables. Quantitative analysis of the data obtained was carried out using SPSS software. The qualitative issues raised during the research are incorporated in explaining associations and other relationships that were suggested by the research findings. Out of the 600-targeted interviews, a total of 211 interviews were successfully conducted. This gives a response rate of $35 \%$. The following section, gives a detailed analysis of the research finding on capital budget practices in the Western Cape.

\section{RESULTS \& DISCUSSION}

The following section discusses the main findings and results of the survey on capital budgeting techniques used in the Western Cape Province.

\subsection{Business Size And Sector}

The respondents were classified according to two criteria, according to business size and according to the sector the business operated under. The research utilised the 2006 Department of Trade and Industry (DTI) definition to classify businesses into small, medium and large business. The DTI defines small businesses as those comprising of $5-50$ employees, medium businesses as those comprising of 51-100 employees and large businesses as those comprising more than 100 employees. From the total 211 respondents $53 \%$ qualified as small businesses while $12 \%$ were medium and the remainder, $35 \%$ were categorised as large businesses. The respondents were further categorised according to 
business type. From the survey, a total of $46 \%$ represented the service sector while $34 \%$ were in retail and the remaining $20 \%$ were involved in manufacturing activities.

\subsection{Capital Budgeting Technique/s Employed}

Accounting literature distinguished between traditional (gut feel) and the modern discounted cash flow techniques. Managers have an option to use either of these techniques or a combination of both. Capital budgeting theory favours the use of discounted cash flow (DCF) techniques as it takes into consideration the time value of money. Brealey \& Myers (2003) explain that managers make capital budgeting decisions based on the assumption

that the primary goal of the business is to maximise the shareholders' wealth. This assumption means that a business will invest in projects that will yield a positive net present value. This view that has been supported by much empirical work for example Graham \& Harvey (2001); Kester et al (1999) and many others, explain why DCF techniques have become dominant techniques for evaluating capital budgeting decisions particularly in large more structured businesses (Graham \& Harvey , 2001).

On the other hand empirical work by Graham \& Harvey (2001) concluded that due to limited managerial skills, non-complicated techniques such as payback methods continue to dominate capital budgeting decision- making in smaller businesses. The respondents in this study were asked to indicate their usage of the different techniques on capital budgeting from a list that included both discounted and non-discounted methods. The results are shown in table 1 , below:

Table 1: Capital budgeting techniques used by businesses

\begin{tabular}{|c|c|c|c|c|c|c|}
\hline Method & IRR & NPV & PI & PP & ARR & No technique \\
\hline Percentage & 28 & 36 & 28 & 39 & 22 & 10 \\
\hline
\end{tabular}

The research findings suggest that the Payback Period (PP) technique (39\% of respondents) was the popular technique used by managers in evaluating capital budgeting decisions. This finding was is line with that of Block (1997), where the payback period was the preferred approach in capital budgeting. This was followed closely by the Net Present Value (NPV) technique (36\%), Internal Rate of Return (IRR) and Profitability Index (both 28\%) and Accounting Rate of Return (22\%).NPV seemed to be more popular than Internal rate of Return (IRR). Ten percent of the respondents indicated that they did not use any techniques associated with their decision making criterion, hence they used their gut feel or intuition to make decisions. Further analysis from the within group indicated that payback period (PP) method was popular amongst small to medium businesses while the large businesses favoured the NPV technique. The predominance of the payback period may be attributed to its simplicity, emphasis on liquidity and response to financial institution, whereby the financial institution is more interested in the business's capacity to pay bank the loan within a set period of time, rather than to specify that a project has a 
positive net present value or that the internal rate of return exceeds the weighted average cost of capital.

\subsection{Level Of Qualification And Capital Budgeting Techniques Used, By Sector}

Given the diverse nature of respondents to the survey, the survey also sought to find out whether there was any relationship between a capital budgeting decision maker and their level of qualification. The following table 2 highlights the formal educational qualifications of the decision makers of the respondents.

\section{Table 2: Qualifications of Personnel Responsible for Capital Budgeting}

\begin{tabular}{|l|l|l|l|l|l|l}
\hline Highest & c grade 12 & Grade & Dinlom & Degree & Post & \\
\hline Percentage (\%) & 10 & 16 & 14 & 21 & 39 & 100 \\
\hline
\end{tabular}

The research results seem to indicate that those decision makers that did not receive formal education

mainly used their intuition or gut feel as compared to those that received formal training that were more inclined to use modern techniques such as DCF. A close analysis however revealed that the use of the DCF was more used by those that received formal finance and accounting training. In some instances, those that did not train formally in accounting practices or had limited educational backgrounds outsourced the accounting activity to experts who advised them accordingly. A closer look at those businesses that used more than two methods indicate that all of them had at least a qualification of a diploma and the majority of them belonged to the post graduate category.

Applying the Chi squared tests, the research findings indicated no association between level of qualification and the number of methods used. However a similar analysis indicated that there was an association between the qualification of a decision maker and the use of NPV ( $\mathrm{p}<0.05)$. This is not surprising as there were more post graduates who had some accounting and finance background in this category who would have received formal training in financial techniques including capital budgeting.

While the payback period technique seemed to be popular, this observation must be viewed cautiously as some respondents indicated that they continued to receive training and were now in a better position to employ qualified employees than before. In addition they stated that they were updating their technology to meet the global competitive wave and as such were in line to use modern capital budgeting techniques. The following table, Table, 3 , shows the percentage usage of the different types of methods by business sector:

\section{Table 3: Capital Budgeting Method by Sector Usage}

\begin{tabular}{l|l|l|l}
\hline & Manufacturing & Retail (\%) & Service (\%) \\
\hline IRR & 24 & 25 & 32 \\
\hline
\end{tabular}




\begin{tabular}{l|l|l|l}
\hline NPV & 24 & 39 & 40 \\
\hline PI & 21 & 29 & 31 \\
\hline PP & 43 & 39 & 36 \\
\hline ARR & 21 & 17 & 26 \\
\hline No technique & 12 & 9 & 11 \\
\hline
\end{tabular}

The research findings suggest that the payback period is more likely used by businesses in the manufacturing sector, those in the services sector prefer net present value and the retails sector used net present value and payback period. The net present value technique seemed to be used to the same extent by businesses in both the retail and service sectors. The accounting rate of return seemed to be the least used technique across all the business sectors. Also consistent with other research (Verbeeten, 2006); the service sector appears to use sophisticated capital budgeting techniques more than the other sectors.

In general using the chi squared test analysis there seemed to be no association between the size of business and the use of the different capital budgeting techniques. The research established that $64 \%$ of businesses surveyed used only one technique, while $32 \%$ of the respondents used between two to three different types of techniques to evaluate capital budgeting decisions. Those that used more than two methods belonged to the post graduate category. The remaining $4 \%$ used no technique or applied gut feel or intuition when it came to capital budgeting decision making.

A closer look at the age of business and number of techniques used suggested that there was no association between age of business and the number of techniques used and between the type of business and the number of techniques used.

\subsection{Business Size \& Capital Budgeting Method Used}

The following table 4 shows the summary of responses given per category of business and the method used

for capital budgeting:

Table 4: Business Category \& Capital Budgeting Technique used

\begin{tabular}{l|l|l|l}
\hline Technique & Small (\%) & Medium (\%) & Large (\%) \\
\hline IRR & 20 & 16 & 43 \\
\hline NPV & 27 & 36 & 50 \\
\hline PI & 27 & 24 & 36 \\
\hline ARR & 17 & 28 & 29 \\
\hline PP & 39 & 38 & 39 \\
\hline No Technique & 15 & $\mathrm{O}$ & 6 \\
\hline
\end{tabular}


The above results further confirm the theory that says as businesses increase in size they begin to use more complicated methods as compared to when they are small businesses. These results support previous empirical research where it was indicated that size has an impact on the capital budgeting practices (Verbeeten, 2006; Farragher, Kleinman \& Sahu, 2001). This research findings show that the PP is more used in small businesses as compared to NPV and IRR which are more used by larger businesses.

When applying the Chi squared tests, the results indicate that there was an association between the size of business and the use of the IRR and NPV techniques $(p<0.05)$. The findings show that the more complicated methods such as IRR and NPV are most favoured by the medium to large businesses as compared to the small businesses. There was an association between size and not using capital budgeting techniques. It appears that size of a business has effect on the use of capital budgeting techniques. The smaller the size of a business, the lesser the use of capital budgeting techniques $(\mathrm{p}<0.05)$. The results also indicated that the PP method was equally used across all sizes of businesses.

\subsection{Sector Of Business And The Most Important Stage In Capital Budgeting}

Gitman (2007) explains that capital budgeting process consist of five distinct but interrelated steps, namely proposal generation, review and analysis, decision making, implementation and follow-up. For the purpose of this study, capital budgeting procedures were categorised into four main stages, namely, project definition, analysis and selection, implementation and finally the review stage.

While each of the steps identified above is important, in practice managers attach different importance to each of these stages. Each of the respondents was asked to rate each of the four stages in order of importance on a scale of 1-4 (4 being most important) This research sought to identify the importance attached to each stage in the capital budgeting process. The following table 5 summarises the responses obtained.

\section{Table 5: Importance of Capital Budgeting Stage}

\begin{tabular}{|l|l|l|l|l|}
\hline $\begin{array}{l}\text { Stages in } \\
\text { capital } \\
\text { budgeting }\end{array}$ & $\begin{array}{l}\text { Project } \\
\text { definition }\end{array}$ & $\begin{array}{l}\text { andysis } \\
\text { selection }\end{array}$ & $\begin{array}{l}\text { Implementatio } \\
\text { neview }\end{array}$ & Review \\
\hline Percentage & $56 \%$ & $26 \%$ & $8 \%$ & $3 \%$ \\
\hline
\end{tabular}

The majority of the respondents, $56 \%$ believed that project definition was the most important stage. The analysis and selection stage were deemed important by $26 \%$ of the respondents and $8 \%$ of the respondents thought that the implementation stage was the most important while $3 \%$ considered the review method as being important. All the sectors and size of businesses felt that the project definition stage to be the most important stage in the capital budgeting process. 
In trying to further clarify the importance attached to each of the stages in capital decision-making, the research further sought to identify the difficulty that managers attached to each of the stages of capital budgeting. Each of the respondents was asked to rate each of the four stages in order of difficulty on a scale of 1-4 (4 being most difficult).The following table 6 gives a summary of the level of difficulty.

Table 6: Level of Difficulty in the Capital Budgeting Stage

\begin{tabular}{|l|c|c|c|c|}
\hline $\begin{array}{l}\text { Stages in capital } \\
\text { budgeting }\end{array}$ & Project definition & Analysis and selection & Implementation & Review \\
\hline Percentage & $32 \%$ & $31 \%$ & $28 \%$ & $3 \%$ \\
\hline
\end{tabular}

It appears that Project definition and Analysis and selection were the most difficult stages (each 31\%) followed by Implementation (28\%).The analysis was pursued further on the different sectors of the business in

order to establish if all the sectors felt the same about the most difficult stage in capital budgeting. Table 7 below shows the most difficult stage in the capital budgeting process by sector.

\section{Table 7: Level of Difficulty and Sector}

\begin{tabular}{|l|l|l|l|l|}
\hline $\begin{array}{l}\text { Stages in Project } \\
\text { capital } \\
\text { budgeting }\end{array}$ & $\begin{array}{l}\text { Analysis and Implementatio } \\
\text { selection }\end{array}$ & Review \\
\hline Manufacturing & $29 \%$ & $24 \%$ & $41 \%$ & $5 \%$ \\
\hline Retail & $28 \%$ & $33 \%$ & $31 \%$ & $3 \%$ \\
\hline Service & $35 \%$ & $35 \%$ & $21 \%$ & $3 \%$ \\
\hline
\end{tabular}

The Implementation stage appeared to be the most difficult stage for the manufacturing sector. Project definition and Analysis and selection and Implementation were generally rated as being the difficult stages by the retail sector whereas Project definition and Analysis and selection were found to be the most difficult stages by the service sector. Interestingly further analysis into the size of the business revealed that project definition was the most difficult stage for small businesses; implementation was the most difficult stage for medium businesses and analysis and selection was the most difficult stage for the large businesses.These findings warrant further research on this discrepancy. It may be assumed that lack of skills, structure of the business, among other factors may account for these differences.

Given the importance attached to each of the processes as stressed by Gitman (2007), the research findings seem to suggest that there is a need for managers to review their perception on the importance they attach to each stage in the process. This may assist them in identifying deficiencies in the methods or in the whole capital budgeting process 
itself. Such a realisation will help organisation to be always on the right footing in terms of their competitive model. The fact that the review process is not deemed important suggests that managers continue to follow the same capital budgeting process without taking into consideration any comments from the review process. Such an approach may have negative repercussions to the business's financial management policy and subsequently may affect the business's overall performance.

\subsection{Interest Rate Charges And Basis Used In Capital Budgeting}

Interest rates play a pivotal role in capital budgeting decisions as they impact on the cost of the capital and therefore on the profitability of the business. The research identified the interest rate that decision maker's use in capital budgeting decisions. Twenty four percent of the respondents used the cost of bank loan as a basis, while $12 \%$ used weighted average cost of capital (WACC) and 15\% used past experience as a basis of determining the cost of capital. Thirty nine percent of the respondents stated that they did not use time value of money in their decisions on capital budgeting. The results also support the findings of Verbeeten (2006), where it was found that about $14 \%$ of the businesses used the weighted average cost of capital as the discount rate when making a capital budgeting decision. There was no association between the size of business and interest rate charged and between the sector of business and interest rate charged. This seems interesting as one may assume that due to pledging of higher collateral in the form of fixed assets the manufacturing sector may pay a lower rate of interest. There was also no association between the age of the business and the interest rate charged. Relationship characteristics, loan and lender characteristics may have an impact on the interest rate charged.

During the period of research, the prime lending rate of interest was $12 \%$. In response to the enquiry on what interest rate managers were charged in their latest investment or project that involved capital budgeting, the research results indicate that those businesses that secured a rate of below 10\% were predominantly from the services sector. The service sector was the largest sector in the sample and was possibly the sector with the greatest growth potential, hence was charged a lower rate of interest compared to the other sectors. In the interest rate category $10-15 \%$, the manufacturing sector accounted for the highest percentage. Thirty one percent of all the businesses were charged an interest rate, which was less than 10\%. Sixty percent of the businesses paid between 10-15\% interest rate. A total of $38 \%$ of those businesses that paid less than $10 \%$ were in the $11-20$ years of existence, while 30\% of those that paid less than 10\% had been in business for less than 10 years. A total of $62 \%$ of the

businesses who were in operation for less than 10 years paid between 10 to $15 \%$ interest rate. Age did not seem to be a factor in the charging of interest rate by the financial institution.

\subsection{Use Of Subjective Technique (Non-Quantitative Techniques)}

The research findings indicate that more than two thirds of respondents used nonquantitative techniques to consider risk when making a decision on investing in fixed 
assets. In terms of business sector on the use of non quantitative techniques, $69 \%$ were from manufacturing; $73 \%$ from the retail sector and $78 \%$ from the service sector.

In addition, the Chi squared test analysis indicated that there was no association between the level of qualification and the use of subjective techniques in considering risk when making a decision about long-term projects. However the finding suggests that those that had a post graduate qualification accounted for the highest percentage, $74 \%$ of the respondents used subjective techniques. Of those that responded positively to subjective techniques, $29 \%$ of them use the method of shortening the payback period, $21 \%$ use expected values of cash flows, $16 \%$ increase the profitability requirements and $16 \%$ use more than one method to consider risk when making a capital budgeting decision. Raising the discount rate could mean shortening the minimum payback period. Also making more conservative estimates of future cash flows and increasing the profitability requirement are used to adjust for risk.

\subsection{Use Of Quantitative Techniques}

A total of $40 \%$ of the respondents used quantitative techniques to consider risk. There was no significant difference between the various sectors and the use of quantitative techniques used. However the research findings indicated that businesses involved in manufacturing were less likely to use quantitative techniques as compared to those in retail and service related businesses.

The results also revealed that those managers that had higher qualifications were more inclined to use quantitative methods more than those that were lesser qualified. A total of $47 \%$ of postgraduates reported using quantitative techniques to consider risk.

\subsection{Capital Budgeting Decisions Makers}

One important dimension of capital budgeting practices relates to the decision maker. Different organisations use different decision makers to make capital budgeting practices. The following table 8 shows decision makers responsible for making capital budgeting decisions in terms of the size of the business.

\section{Table 8: Capital Budgeting Decision Makers}

\begin{tabular}{|l|l|l|l|}
\hline Decision Maker & Small (\%) & Medium (\%) & Large (\%) \\
\hline Owner & 80 & 56 & 35 \\
\hline Operations & 5 & 4 & 21 \\
\hline Finance & 18 & 32 & 38 \\
\hline Team Decision & 9 & 16 & 27 \\
\hline
\end{tabular}

The above results show that at least a third of business owners in the Western Cape are directly responsible for capital budgeting decision. The findings further suggest that different business level managers have limited influence on capital budgeting decision- 
making. The influence however increases with the increase in the business's size. It would seem that finance section had a significant influence in all decisions making scenarios.

A similar view can be expressed as regards the role played by teams in capital budgeting. One plausible explanation that respondents indicated relate to the nature of small businesses. The majority of the interviewees in the small business category who operated their businesses had limited operational structures generally associated with larger corporations. This may be a reason why owners dominated capital budgeting decisionmaking in small businesses. The same however cannot be attributed to larger businesses as they have more formalised structures and large work forces. Consequently, the above results suggest that any policy issues or training related issues associated with capital decisionmaking should be directed towards owners, as they are active in capital decision-making.

\section{CONCLUSION}

This research has revealed the nature of capital budgeting practices in the Western Cape. In particular capital budgeting practices decision makers were considered, the impact of the business size, level of education of decision makers, the process of capital budgeting and lastly the association between certain variables and capital budgeting were all considered. The research findings in some cases, supported theory for example on the aspect of the level of education and method used while in some instances the results were contrary to theory for example the payback method still remains a popular method among the different sizes and different types of businesses despite its disadvantages.

\subsection{LIMITATIONS OF THE STUDY AND FUTURE RESEARCH}

The definition of company sized was based on the on the number of employees. Other indicators of business size such as capital employed; turnover were not considered. The research did not look into such aspects as race and gender of the managers involved in capital budgeting. It is proposed that future researches may look into these variables to determine their impact on capital budgeting. Future researches on capital budgeting in South Africa should also investigate whether the use of more than one method in capital budgeting has any impact on the financing of capital budgeting expenditures and to what extent it affects the accept/reject decision.

\section{AUTHOR INFORMATION}

Author 1

First name: Pradeep

Surname: Brijlal

Institution: University of the Western Cape

Position: Lecturer

Qualification: B.Sc; HDE (post graduate); MBA

Work Experience:

I am a lecturer in the School of Business and Finance at the University of the Western Cape, South Africa. I am 
involved in lecturing and coordinating various finance, investments and business management modules, both at the undergraduate and graduate levels. I am also a business advisor; involved in material development in finance related modules and been involved in reviewing finance text books.

\section{Research areas of interest:}

Investments; entrepreneurship and finance.

\section{Author 2}

First name: Lemay

Surname: Llorente Quesada

Institution: University of the Western Cape Position: Lecturer

Qualification: B.Com; B.Com Finance (Honours); M.Com

Work Experience:

I have been teaching in the field of Commerce at the Central University of Las Villas in Cuba and at the University of the Western Cape, South Africa. I have been involved in teaching and tutoring in Financial Management in the

School of Business and Finance and Business Modules in Academic Development Department.

\section{Research areas of interest:}

SMME development, entrepreneurship and finance. 


\section{REFERENCES}

1. Arya, A., Fellingham, J.C and Glover, J.C. (1998). Capital Budgeting: Some exceptions to the Net Present Rule, Issues in Accounting Education. Vol. 13 (3) pp. 499-508.

2. Block, S. 1997. Capital budgeting techniques used by small business firms in the 1990s, The Engineering Economist, Vol.42 (4) pp. 289-302.

3. Brealey, R.A and Myers, S.C. 2003. Principles of Corporate Finance, $5^{\text {th }}$ Edition, McGraw-Hill.

4. Danielson, M.G and Scott, J.A. 2006. The Capital Budgeting Decisions of Small Businesses, Journal of Applied Finance, Fall/Winter, pp. 45-56.

5. Drury, C and Tayles, M. 1996. UK Capital Budgeting Practices: Some additional service evidence, The European Joumal of Finance. Vol. 2, pp. 371-388.

6. Eschenbach, T and Cohen, R. 2006. Which Interest Rate for Evaluating Projects? Engineering Management Journal, Vol. 18 (3) September, pp. 11-19.

7. Farragher, E.J., Kleinman, R.T and Sahu, A.P. 2001. The association between the use of sophisticated capital budgeting practices and corporate performance, Engineering Economics. Vol 46 (4), pp. 300-311.

8. Gitman, L.J. 2007. Principles of Managerial Finance, $11^{\text {th }}$ Edition, Pearson International.

9. Graham, J.R and Harvey, C.R. 2001. The theory and Practice of Corporate Finance: Evidence from the field, Journal of Financial Economics, Vol. 6o (2-3) pp.187-243.

10. Hermes, N., Smid, P and Yao, L. 2007. Capital Budgeting Practices: A comparative study of the Netherlands and China, International Business Review, Vol 16, pp. 630654 .

11. Horngren, C., Foster, C and Datar, S. 1997. Cost Accounting. Englewood Cliffs, NJ: Prentice Hall.

12. Jog, V.M and Srivastava, A. K. 1995. Capital Budgeting Practices in Corporate Canada, Financial Practice \& Education, Fall/Winter, pp. 37-42.

13. Kwak, W., Shi, Y., Lee, H., and Lee C.F.1996. Capital Budgeting with Multiple Criteria and Multiple Decision Makers. Review of Quantitative Finance and Accounting, Vol 7, pp. 97-112

14. Kester, W and Chong, TR. 2001. Capital Budgeting Practices of listed businesses in Singapore, Singapore Management Review, pp. 9-23.

15. Kester, W., Chong, T.R., Echanis, E.S., Haikal, S., Isa, M., Sckully, M.T., Tsui, K.C and Wang, C.J. 1999. Capital Budgeting Practices in the Asia-Pacific region: Australia, Hong Kong, Indonesia, Malaysia, Philippines, and Singapore, Financial Practice and Education, Spring/Summer, pp. 25-33.

16. Lazaridis, I.T. 2004. Capital Budgeting Practices: A Survey in the businesses of Cyprus, Journal of Small Business Management, Vol 42 (4), pp. 427-433.

17. McDonald, R.L. 1998. Real Options and Rules of Thumb in Capital Budgeting. Working Paper. Finance Department, Kellog School.

18. Pike, R. 1996. A longitudinal survey on Capital Budgeting Practices, Journal of Business Finance and Accounting, Vol 23 (1) January, pp. 1-15. 
19. Pike, R. H. 1988.The Capital Budgeting Revolution, Management Accounting, Vol 66, pp. 28-30.

20. Ross, S. 1995. Uses, abuses and alternatives to the net present value rule, Financial Management (Autumn), pp. 96-102.

21. Sandahl, G and Sjogren, S. 2003. Capital budgeting methods among Sweden's largest groups of companies: The State of the art and a comparison with earlier studies, International Journal of Production Economics, Vol 84, pp. 51-69.

22. Verbeeten, F.H.M. 2006. Do organisations adopt sophisticated capital budgeting practices to deal with uncertainty in the investment decision? A research note. Management Accounting Research, vol 17, pp. 106-120. 